\title{
Soft Tissue Sarcoma of the Trunk and Extremities by AJCC v8 Stage
}

National Cancer Institute

\section{Source}

National Cancer Institute. Soft Tissue Sarcoma of the Trunk and Extremities by A/CC v8 Stage. NCl Thesaurus. Code C136694.

A term that refers to the staging of soft tissue sarcoma of the trunk and extremities, following the rules of the TNM AJCC v8 classification system. 